\title{
Nova ruralidade e o modelo de desenvolvimento no bioma Cerrado: as várias "marchas" para o Oeste do Brasil
}

\author{
Pedro Araújo Pietrafesa \\ Programa de Pós-Graduação em Desenvolvimento e Planejamento Territorial da Pontifícia Universidade Católica \\ de Goiás (Puc/Goiás) \\ José Paulo Pietrafesa \\ Programa de Pós-Graduação em Educação da Universidade Federal de Goiás (Puc/Goiás)
}

Recebido: 23/11/2015 Versão revisada (entregue): 12/02/2016 Aprovado: 18/02/2016

\begin{abstract}
Resumo
O presente artigo tem o objetivo de analisar como as atividades rurais levadas a efeito no Centro-Oeste contribuíram para o desenvolvimento da região. O trabalho parte do pressuposto de que o setor agroindustrial colaborou não só para a ocupação do interior do Brasil, mas também para a urbanização dos estados de Goiás, Mato Grosso e Mato Grosso do Sul. Além disso, a política de desenvolvimento regional esteve inserida, durante as décadas de 1960 a 1980, num contexto nacional de substituição de importações. No período recente, os estados do Centro-Oeste vêm experimentando a expansão do complexo industrial sucroenergético, consubstanciando uma "nova marcha para o Oeste brasileiro". Neste ultimo caso, conta-se com a concessão de novos incentivos fiscais e com a disponibilidade de recursos orçamentários para a instalação e consolidação do setor.
\end{abstract}

Palavras-chave | Centro-Oeste; Cerrado; desenvolvimento regional; marcha para o Oeste; setor agroindustrial.

Código JEL | O13; Q13; R58.

\section{NEW RURALITY AND THE DEVELOPMENT MODEL OF THE CERRADO BIOME: THE VARIOUS "MARCHES" TO THE BRAZILIAN WEST}

\begin{abstract}
The paper aims to analyze how the rural activities engaged in the Brazilian Midwest contributed to regional development. The study assumed that the agro industrial sector collaborated not only to the occupation of Brazilian up-country, but also to the urbanization of the states: Goiás, Mato Grosso and Mato Grosso do Sul. Furthermore, the regional development policy was inserted during the decades of 1960 to 1980, in a national context of imports substitution. Currently, the Midwest states experienced the expansion of sugar and ethanol industrial complex with new tax breaks and budget resources to the settlement of the sector.
\end{abstract}


Keywords | Agro industrial sector; Cerrado; marches to the West; Midwest; regional development.

JEL-Code | O13; Q13; R58.

\section{NUEVA RURALIDAD Y EL MODELO DE DESARROLLO EN EL BIOMA DEL CERRADO: LAS DIFERENTES “MARCHAS” AL OESTE DEL BRASIL}

\section{Resumen}

El artículo tiene como objetivo analizar cómo las actividades rurales realizadas en el CentroOeste contribuyeron para el desarrollo de la región. El trabajo parte de la suposición de que el sector agroindustrial contribuyó no solamente en la ocupación del interior de Brasil, sino también para la urbanización de los estados de Goiás, Mato Grosso y Mato Grosso do Sul. Además, la política de desarrollo regional estaba inserida, durante las décadas 1960-1980, en un contexto nacional de sustitución de importaciones. Actualmente, los estados del Centro-Oeste vienen experimentando la expansión del complejo industrial sucroenergético, suponiendo una "nueva marcha hacia el Oeste brasileño". En este último caso, se cuenta con nuevos incentivos fiscales y la disponibilidad de recursos presupuestarios para la instalación y consolidación del sector.

Palabras-clave | Centro-Oeste; Cerrado; desarrollo regional; marcha al Oeste; sector agroindustrial.

Código JEL | O13; Q13; R58.

\section{Introdução}

O presente trabalho tem o objetivo de analisar o processo de desenvolvimento econômico da região Centro-Oeste. Optou-se por iniciar os estudos pelos anos 1940, por ser uma importante referência cronológica na ocupação espacial desta região em pelo menos dois aspectos: o primeiro está relacionado à ampliação quantitativa da população, que teve inicio com a "Marcha para o Oeste" (LENHARO, 1986). Essa "marcha" foi planejada durante a ditadura do Estado Novo, no Governo Getúlio Vargas, a partir de 1938. O governo encontrou nos espaços vazios do Centro-Oeste a solução para alguns problemas de caráter social que o pressionavam. De um lado, os pequenos agricultores do Sul do Brasil que reivindicavam Reforma Agrária e mais espaço para trabalhar a terra; de outro, os retirantes do Nordeste que fugiam da seca e da cerca. O segundo aspecto relaciona-se à abertura das novas frentes de expansão agrícola que colocou em atividade milhões de hectares de terras no sistema de produção agropecuário.

Para alcançar o objetivo proposto, o artigo está dividido em quatro partes. A primeira delas abordará o início do processo de expansão econômica e populacional em direção ao interior do Brasil. A segunda parte discutirá a descentralização das políticas de incentivo às atividades econômicas, realizada por 
meio da criação de superintendências regionais de desenvolvimento durante o regime militar, bem como as políticas dos governos democráticos que buscaram melhorar o setor produtivo no Centro-Oeste brasileiro, demonstrando que a agropecuária foi o ramo escolhido para impulsionar a economia na região. A terceira parte tratará da nova "Marcha para o Oeste" que os estados de Goiás, Mato Grosso e Mato Grosso do Sul vivenciaram nos últimos anos, com a instalação do complexo industrial sucroenergético nessas unidades da federação. Na quarta e última parte será apresentada a conclusão do artigo.

\section{A primeira "Marcha para o Oeste" e as fronteiras agrícolas como fatores de desenvolvimento da região Centro-Oeste}

A construção de Brasília e a consequente instalação do Distrito Federal contribuíram significativamente, já a partir dos anos 1950, para a atração de contingentes populacionais em direção a Goiás, Mato Grosso e Mato Grosso do Sul. Anteriormente, a construção da cidade de Goiânia, concebida para sediar a nova capital do estado de Goiás, no início da década de 1930, também contribuiu para o crescimento populacional da Região. No entanto, a "abertura de fronteiras agrícolas", em momentos históricos distintos, é o principal fator de ocupação e desenvolvimento da Região, que contou, ainda, com forte ação do Estado como mola propulsora desse movimento. $\mathrm{O}$ primeiro desses movimentos pode ser identificado como a "marcha para o oeste", que ocorreu na região Centro-Oeste do Brasil nos primeiros anos do século XX, de acordo com Lenharo (1986, p. 5556):

A cruzada da Marcha para o Oeste, seja no plano discursivo, seja no plano das justificativas administrativas, constitui um precioso exemplo dessa fabricação de imagens. Elaboradas crucialmente na virada do ano novo de 38, pouco depois do golpe, e re-trabalhada cuidadosamente nos anos seguintes, a Marcha para o Oeste foi calcada propositalmente na imagem da Nação que caminha pelas próprias forças em busca de sua concretização. Procede do discurso de Vargas a afirmação de que a conquista da brasilidade seria ultimada através da interiorização do país: 'O verdadeiro sentido da brasilidade é a marcha pra o oeste' (discurso de Getúlio Vargas proferido em janeiro de 1939 em São Paulo).

No caso de Goiás esta ocupação regional pode ser vista da seguinte forma:

Com a Marcha para o Oeste, Goiás se insere na política de substituição de importações, que visava industrializar o Sul e Sudeste brasileiro, enquanto a periferia era encarregada da produção de gêneros 
alimentícios e matéria-prima para ampliar o abastecimento dessas regiões (VAZ, 1989, p. 42).

Este movimento funcionou como o instrumento ideológico da ocupação regional, na medida em que trazia uma justificativa maior para esse fenômeno, uma vez que inseriu a noção de projeto de nação ao conjunto do país. Portanto, não foi uma simples medida regional ou local de criação de novos núcleos de assentamento de populações agrícolas de baixa renda com vistas a uma melhoria na qualidade de vida. Era entendido como um projeto de importâncias maiores, feito em nome da grandeza nacional. Quem se habilitasse a fazer parte desse projeto fazia-o ciente disso, mas numa espécie de "subjetividade forçada", na medida em que o discurso requeria a ação do sujeito, mas reforça essa mesma ação através da utilização dos discursos da brasilidade (SILVA, 2004).

Num segundo momento desta "Marcha", os investimentos governamentais para a criação de redes de transporte e armazenagem foi de vital importância, assim como o desenvolvimento de pesquisas agropecuárias e a concessão de crédito agrícola subsidiado foram decisivos na implantação dos projetos de colonização e desenvolvimento da agricultura intensiva na Região, a partir da década de 1960 (PIETRAFESA, 2002), que pode ser identificado como segundo ciclo migratório para a região.

A devida compreensão do processo acima ressalta, ao mesmo tempo, a compreensão do papel do "Estado Nacional" na sua política de ocupação dos espaços vazios e de integração do país. A visão de integração territorial do sertão brasileiro, como a representação do sentido de nacionalidade, configura-se como um dos elementos discursivos do Estado Novo, instrumentalizado na Marcha para Oeste. "O Estado se projetava como o elemento dotado de poder de representação, na medida em que buscava promover tanto a expansão territorial quanto à integração de regiões isoladas do sertão com o litoral 'moderno e civilizado'." (SILVA, 2004). O projeto de ocupação do Oeste não se limitava a ocupação geográfica da fronteira, mas em fazer dessas áreas, então ocupadas, parte efetiva e produtiva do território e da nação brasileira.

Leone (2004, p. 24) complementa a visão anteriormente apresentada, identificando o processo já na década de 1930, em que percebe a criação de canais de desenvolvimento para a região.

Era esse Goiás que passou a ser o alvo do governo federal a partir da década de 30, como objetivo da interiorização que pretendia. A sua estrutura social apresentava-se, pois, como conveniente balão de ensaio para testar tal pretensão. Se fosse possível expandir a área de influência da economia de mercado do Sudeste até o cerrado goiano, então a interiorização poderia acontecer nas demais regiões. Vencer as resistências dos donos do poder local não se constituía em um projeto 
para o país, mas um significativo passo na direção da unificação nacional.

Um dos motores propulsores para a rápida ampliação da fronteira agrícola na região Centro-Oeste foi a possibilidade de valorização de suas terras, principalmente impulsionadas pela abertura das lavouras de arroz e pastagem, além de possuir uma topografia relativamente plana. Como os preços existentes antes das décadas de 1960 e 1970 eram extremamente baixos, isso incentivava a migração de populações sulistas para a região. Mesmo as áreas mais remotas do estado constituíram atração para investimentos ligados à expansão capitalista no campo. Conforme Estevam (1998, p. 179).

[...] aos baixos preços da terra vigorantes em 1980 na maior parte do Estado do Mato-Grosso e no centro-norte de Goiás estaria vinculada a possibilidade de um ritmo mais acelerado de incorporação de novas áreas à produção por parte tanto de empresários ou grupos econômicos do Sul e Sudeste quanto de fazendeiros da região que expandem suas atividades adquirindo terras nas áreas mais distantes, a preços muito inferiores àqueles das áreas de procedência [...].

À medida em que as fronteiras agrícolas expandiam-se, ou as frentes de expansão se alargavam, setores de serviço e comércio acompanhavam a mesma lógica. A região Centro-Oeste viu, nestes momentos históricos, a consolidação de centenas de municípios espalhados pelo interior de cada estado. A imensa maioria das cidades existentes na região foi criada depois de 1930. O que se pretende afirmar é que na medida em que avançam o desmatamento e a agropecuária, avança o processo de urbanização e criação das pequenas e médias cidades, bem como das capitais dos estados. Ou seja, a economia rural deu e dá sustentação à urbanização. A região Centro-Sul do Brasil esteve presente nas preocupações das autoridades federais e foi incluída em uma agenda especial para a ocupação de suas terras de cerrado através da Comissão de Desenvolvimento do Centro-Oeste posteriormente esta Comissão foi transformada em Superintendência de Desenvolvimento do Centro-Oeste (SUDECO).

\section{A política de descentralização do desenvolvimento: da criação das Superintendências de Desenvolvimento durante o governo militar às políticas dos governos democráticos das décadas de 1990 e início dos anos 2000}

Para Estevam (1998), esse programa federal de descentralização tinha como objetivo avançar em direção às fronteiras agrícolas e os espaços considerados 
vazios do território nacional. Esta movimentação oficial criou um processo de interiorização do país para atrair produtores agrícolas e despertar a atenção dos grandes empresários das demais regiões do Brasil e também de agentes internacionais. Assim, visando uma maior produtividade agrícola, a região foi incorporada ao novo modelo produtivo do país, caracterizando-se pela utilização de alta tecnologia e, de certa forma, reduzindo as oportunidades de empregos permanentes no meio rural.

Em decorrência deste "modelo de desenvolvimento" brasileiro e dos programas mencionados o Estado de Goiás sofreu consideráveis transformações na sua estrutura sócio-produtiva: a técnica de produção foi alterada pelos segmentos industriais a montante (indústrias vendedoras de máquinas e insumos) e a jusante (indústrias transformadoras da matéria prima agropecuária) e a redução do tempo de trabalho necessário/período de produção modificaram as relações socioeconômicas regionais eminentemente no centro-sul do estado (ESTEVAM, 1998, p. 170).

A partir da criação da SUDECO, em 1967, foram observados vários "corredores" de desenvolvimento na região do Centro-Oeste brasileiro, fator reforçado também pela criação da Superintendência de Desenvolvimento da Amazônia (SUDAM). Estes corredores estavam se caracterizando a partir da produção de grãos (soja, arroz), mas também incorporaram a extensão das lavouras de cana e abertura das Usinas e Destilarias de álcool e açúcar (ESTEVAM, 1998).

Entre os corredores de desenvolvimento em Goiás podemos destacar o corredor ao longo da estrada Belém-Brasília. Os investimentos ao longo desta rodovia evidenciaram o estilo das políticas "desenvolvimentistas" federais: na região norte de Goiás despontou a presença de grandes fazendas na abrangência da Belém-Brasília. Os objetivos da SUDAM foram claros no sentido de favorecer a grande propriedade; para se ter uma idéia do impacto sobre a estrutura agrária "até 1985, foram aprovados 626 projetos, 215 no Estado do Mato-Grosso e $53 \mathrm{em}$ Goiás, cujo tamanho médio das propriedades era de cerca de 21 mil hectares, em alguns casos ultrapassando o significativo tamanho de 100 mil hectares" (ESTEVAM, 1998, p. 164).

A década de 1960 marca uma grande flutuação no crescimento populacional da região Centro-Oeste do Brasil. É, então, inaugurado um segundo ciclo migratório, que podemos denominar a "2a Marcha para o Oeste": 
Tabela 1 Crescimento da população residente, Centro-Oeste, 1960 a 2014

\begin{tabular}{lrrrccc}
\hline Estado & 1960 & 1970 & 1980 & 1991 & 2000 & 2014 \\
\hline MS & - & & -1.369 .567 & 1.778 .741 & 2.078 .070 & 2.619 .657 \\
MT & 889.539 & 1.597 .090 & 1.138 .691 & 2.022 .524 & 2.505 .245 & 3.224 .357 \\
GO & 1.913 .289 & 2.938 .677 & 3.859 .602 & 4.012 .562 & 5.004 .197 & 6.523 .222 \\
DF & 140.164 & 537.492 & 1.176 .935 & 1.598 .415 & 2.051 .146 & 2.852 .372 \\
\hline Total & 2.942 .992 & 5.073 .259 & 7.544 .795 & 9.412 .242 & 11.638 .658 & 15.219 .608 \\
\hline
\end{tabular}

Fonte: IBGE (2015).

A população na região Centro-Oeste cresceu quase sete vezes nos últimos 50 anos. De acordo com as pesquisas censitárias, o número de habitantes em 1960 era aproximadamente três milhões, enquanto na pesquisa de 2014 houve o registro de 15 milhões de pessoas.

Dentro dos vários projetos de crescimento econômico administrados pelos governos, o norte de Goiás (que até a década de 1970 era uma região desabitada) esteve também contemplado no Programa de Redistribuição de Terras e de Estímulo à Agroindústria Norte e Nordeste (PROTERRA). Esse programa beneficiou a ocupação de áreas do Centro-Oeste, fornecendo recursos a projetos de colonização. Segundo Estevam (1998), entre 1967 e 1986 foram implantados 108 projetos em 2,9 milhões de hectares. Dessa forma, o autor consegue mostrar que, realmente, não só Goiás, mas também toda a região Centro-Oeste do Brasil recebeu vários incentivos governamentais, propiciando um crescimento significativo na expansão da agricultura em geral.

Além dos citados programas federais para incentivar o desenvolvimento e a ocupação espacial da região Centro-Oeste do Brasil, é válido identificar a criação do Programa de Desenvolvimento dos Cerrados (POLOCENTRO). Seu objetivo era a modernização das atividades agropecuárias no Centro-Oeste, estruturando-se em algumas atividades básicas, especificamente na dotação de infraestrutura, pesquisas agropecuárias e concessão de linhas de financiamento rural. O esforço do Programa concentrou-se no aprimoramento da tecnologia de cultivos: um arsenal de assistência técnica foi espalhado pela região dos cerrados com técnicos de nível superior voltados para crescimento e expansão das atividades agrícolas. Dessa forma, houve um fortalecimento significativo no processo de capitalização do campo (ESTEVAM, 1998). Segundo o autor, a participação do crédito no produto bruto da agricultura do Centro-Oeste ostentou curva fortemente ascendente: em 1969 era de 23,4\%, e em 1976 já atingia 94,7\%.

Portanto, as alterações na ordem econômica da região Centro-Oeste foram evidentes. Em função dos programas governamentais implementados, as relações 
técnicas de produção no campo transformaram-se, repercutindo na vida social, econômica e regional. As forças produtivas da agricultura que eram utilizadas foram substituídas por novas forças do tipo industrial. A mecanização da agricultura, nova divisão tecnológica do trabalho e o consequente aumento da produtividade caracterizaram a mudança da região.

Tabela 2 Produção dos principais produtos agrícolas, Mato Grosso, 1989 a 2003 (toneladas)

\begin{tabular}{rrrrrrrrrr}
\hline Safra & $\begin{array}{c}\text { Algodão } \\
\text { Herbáceo }\end{array}$ & $\begin{array}{c}\text { Arroz } \\
\text { (em casca) }\end{array}$ & $\begin{array}{l}\text { Café } \\
\text { (em } \\
\text { coco) }\end{array}$ & Feijão & Milho & Soja & Sorgo & Trigo \\
\hline $1989 / 90$ & 57.634 & 420.722 & 78.837 & 30.890 & 618.973 & 3.064 .715 & 10.211 & 11 \\
$1994 / 95$ & 87.458 & 762.327 & 18.059 & 23.220 & 1.226 .157 & 5.491 .426 & 33.040 & 0 \\
$1995 / 96$ & 73.553 & 721.793 & 9.383 & 20.472 & 1.514 .658 & 5.032 .921 & 78.487 & 0 \\
$1996 / 97$ & 78.376 & 694.904 & 16.170 & 19.988 & 1.520 .695 & 6.060 .882 & 109.818 & 0 \\
$1997 / 98$ & 271.038 & 776.502 & 27.474 & 16.343 & 948.659 & 7.228 .052 & 63.427 & 1.500 \\
$1998 / 99$ & 630.406 & 1.727 .339 & 22.781 & 26.132 & 1.118 .851 & 7.473 .028 & 69.239 & 762 \\
$1999 / 00$ & 1.002 .836 & 1.851 .517 & 22.824 & 24.663 & 1.429 .672 & 8.774 .470 & 157.620 & 1.800 \\
$2000 / 01$ & 1.525 .376 & 1.151 .816 & 53.582 & 30.424 & 1.743 .043 & 9.533 .286 & 195.374 & 750 \\
$2001 / 02$ & 1.141 .211 & 1.192 .447 & 59.509 & 39.578 & 2.313 .708 & 11.702 .165 & 139.217 & $2.640^{(1)}$ \\
$2002 / 03$ & 1.104 .249 & 1.255 .634 & 36.653 & 52.556 & 2.866 .475 & 12.719 .203 & 297.514 & - \\
\hline
\end{tabular}

Fonte: IBGE.

${ }^{(1)}$ Fonte: CONAB.

Elaboração: SEPLAN-MT/Superintendência de informações, 2003.

Obs: Unidade de medida da produção de café utilizada a partir da safra 2000/2001 é o grão beneficiado

O estado do Mato Grosso, com uma produção agrícola incipiente no triênio 1968/70 (no período, a produção se concentrava no atual estado do Mato Grosso do Sul) recebeu forte impulso nos anos seguintes. Entre os triênios 1979/81 e 1995/1997, Mato Grosso do Sul e Goiás dobraram em termos físicos sua produção agrícola e pecuária, sendo que o estado do Mato Grosso teve seu sistema de produção praticamente multiplicado por mais de cinco vezes, saltando de 1,3 milhões de toneladas para 7,6 milhões de toneladas atuais, aumentando sua participação na produção nacional a partir da casa dos de 3\% para $10 \%$ no triênio 1979/1981 e de 20\% para 40\% da produção no período de 1995/1997 dentro da região Centro-Oeste. O destaque pode ser atribuído à produção de soja, milho e 
algodão. "Neste período a participação do Mato Grosso na produção brasileira de soja subiu de $1 \%$ para mais de $20 \%$, possuindo também a maior produtividade por área, a qual supera os $2.500 \mathrm{~kg} / \mathrm{ha} . "$ (DINIZ, 1999).

Embora a expansão da produção agrícola incorpore terras muitas vezes utilizadas pela pecuária, a grande disponibilidade de terras permitiu também a expansão desta última, principalmente na parte norte do estado do Mato Grosso (PIRES, 2000). Para se ter ideia sobre esse montante, o rebanho bovino da região cresceu de 11 milhões de cabeças, em 1960, para 46 milhões, em 1990, e para mais de 50 milhões atualmente, ampliando a sua participação de $20 \%$ para mais de $30 \%$ do total nacional (DINIZ, 1999 apud PIRES, 2000).

Em 2001, a segunda região no Brasil em área plantada é o Centro-Oeste. Conforme Silveira Filho (2004, p. 39):

O Estado do Mato-Grosso apresenta uma participação de $52 \%$ na região e $12 \%$ no universo nacional. Já Goiás apresenta 29\% da participação da região e 7\% do total brasileiro. Nesses Estados, há uma indicação de uma forte intensificação das atividades de aviação agrícola devido, principalmente, à cultura da soja, com excelente perspectiva de mercado e preço.

Sendo assim, a região possui um enorme potencial de crescimento agrícola, visto que o Centro-Oeste foi muito visado por Programas governamentais como sendo uma nova fonte econômica para o país com a modernização da agricultura e que vem crescendo cada vez mais. O conjunto de avanços presenciados nas atividades agrícolas das culturas de milho e soja ampliou consideravelmente a migração e a implantação de complexos agroindustriais da região Sul e Sudeste para região Centro-Oeste (Swift, Anderson Clayton, Samrig, Bayer, Basf, Monsanto, Bunge, Cargiil, Unilever, dentre outras). Estas empresas atuam nas áreas de processamento de produtos químicos (ou também podemos chamar de padrão químico), armazenagem e comercialização de grãos. No decorrer das décadas de 1980 e 1990 as mesmas culturas (milho e soja) facilitaram a migração de outros tipos de complexos industriais à região, os criadores de aves e porcos (Sadia, Perdigão e Seara, entre outros). Este setor foi beneficiado com forte aparato estatal, uma vez que encontrou subsídios através dos Programas do Fundo Constitucional do Centro-Oeste (FCO), bem como de financiamentos do Banco Nacional de Desenvolvimento Econômico e social (BNDES). Além destes programas federais, as empresas contaram com ajuda dos governos estatuais através de políticas de isenção fiscal (ICMs, por exemplo).

O avanço em terras do Cerrado foi facilitado, também, pela topografia e pela facilidade de corrigir o solo. A mecanização foi outra grande promotora de crescimento econômico na região (ou também podemos chamar de padrão 
mecânico). Somados à migração de indústrias e à utilização de equipamentos mecânicos, o Centro-Oeste recebeu outra novidade: a rede nacional da Empresa Brasileira de Desenvolvimento Agropecuário (EMBRAPA) instalou várias unidades na região para fazer pesquisas de melhoramento genético nas áreas de arroz/feijão; cultura do milho e da soja e ainda nas áreas de pecuária. Assim, o Centro-Oeste fechou o ciclo de incorporação dos espaços rurais no modo de produção capitalista. Consolidou-se o padrão químico-genético-mecânico (QMG). A terra passou a ser vista apenas como mais um insumo dentro do sistema de produção. Assim, as bases das relações de produção estão voltadas para ganhos de produtividade e de qualidade com baixo custo e diminuição na utilização de mãode-obra (PIETRAFESA, 2008).

\section{Mapa 3 Identificação do fluxo migratório na produção de grãos (Sul- Centro-Oeste)}

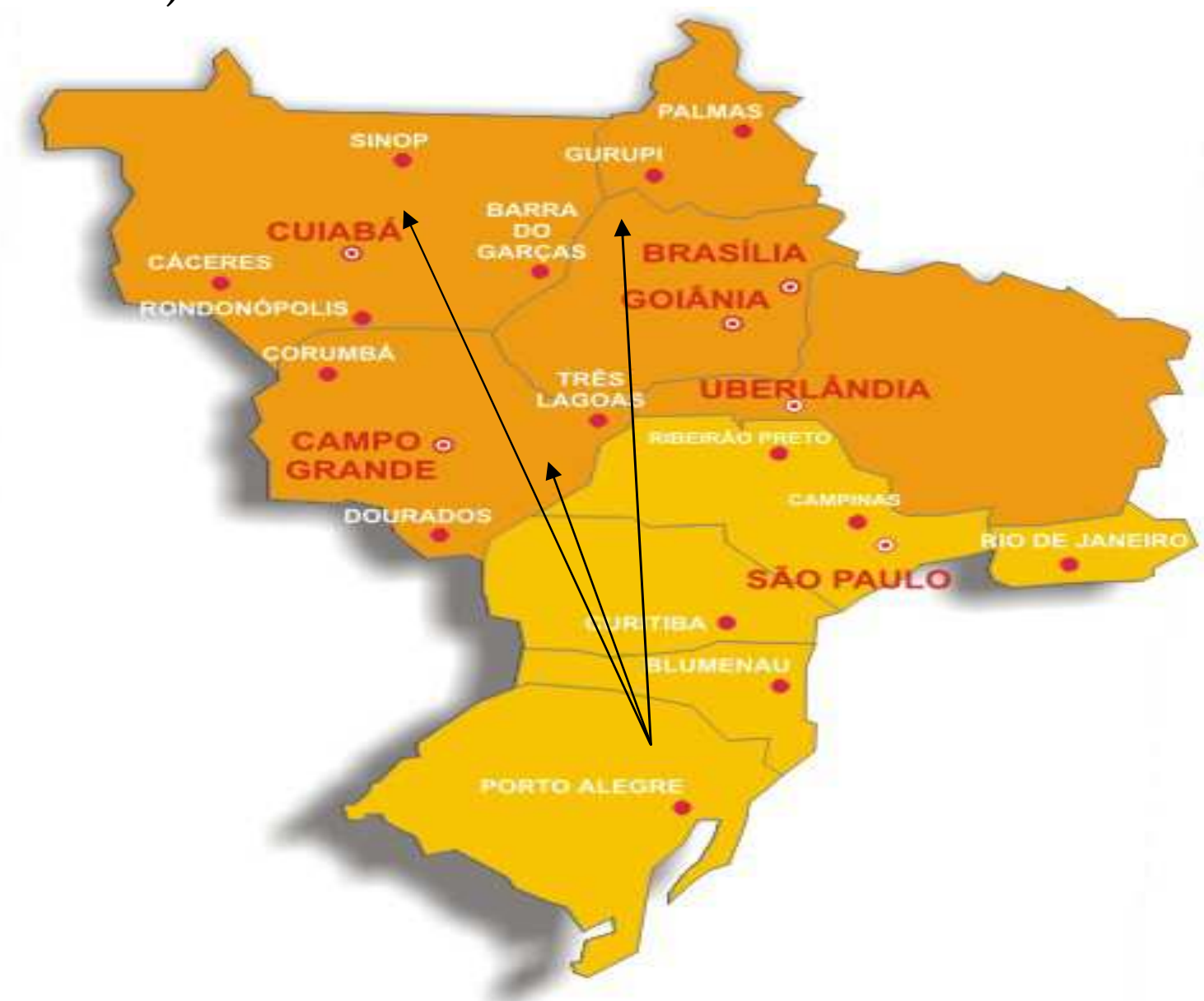

Elaboração: José Paulo Pietrafesa.

A Tabela 3 confirma os dados apresentados sobre o crescimento na produção de aves e suínos na região Centro-Oeste. Porém, é importante destacar a expansão da produção de bovinos, pois tradicionalmente este sistema produtivo inicia as 
transformações dos "espaços vazios". A fronteira é aberta com as derrubadas, em seguida, as queimadas, e somente após alguns anos a soja e o milho ocupam estas terras. Os dados abaixo indicam que, novamente, o Mato Grosso foi o estado que teve a maior densidade no crescimento dos rebanhos.

Tabela 3 Principais rebanhos da região Centro-Oeste em 1985 e 1996

\begin{tabular}{lrrrrrr}
\hline \multirow{2}{*}{ UF } & \multicolumn{3}{c}{1985} & & \multicolumn{3}{c}{1996} \\
\cline { 2 - 7 } & \multicolumn{1}{c}{ Bovinos } & Suínos & \multicolumn{1}{c}{ Aves } & Bovinos & \multicolumn{1}{c}{ Suínos } & Aves \\
\hline MS & 15.017 .906 & 400.656 & 2.801 .000 & 19.754 .356 & 508.813 & 10.971 .000 \\
MT & 6.545 .956 & 671.150 & 3.673 .000 & 14.438 .135 & 671.789 & 13.066 .000 \\
GO & 14.476 .565 & 1.442 .031 & 11.448 .000 & 16.488 .390 & 1.004 .074 & 13.281 .000 \\
DF & 75.866 & 34.981 & 2.446 .000 & 85.615 & 69.321 & 5.778 .000 \\
Total & 36.116 .293 & 2.548 .818 & 20.368 .000 & 50.766 .496 & 2.253 .997 & 43.096 .000 \\
\hline
\end{tabular}

Fonte: IBGE, Produção da Pecuária Municipal (1985) e Censo Agropecuário 1995-1996.

Conforme mencionado anteriormente, durante as décadas de 1980 e 1990 a região Centro-Oeste foi alvo de um intenso investimento para a sua ocupação baseada no uso agrícola e na pecuária. A Tabela 4 e a Tabela 5, abaixo, indicam as variações na utilização das terras e demonstram a grandiosidade das mudanças espaciais da região. Programas desenvolvidos sobretudo a partir dos anos 1970, tais como o Programa Nipo Brasileiro de Desenvolvimento dos Cerrados (PRODECER) e o Programa de Desenvolvimento do Cerrado (POLOCENTRO) tiveram papel importante na instalação da infraestrutura para a abertura da fronteira agrícola. 
Tabela 4 Utilização de terras no Centro-Oeste, 1985 (hectares)

\begin{tabular}{lrrrrrrrrr}
\hline UF & $\begin{array}{c}\text { Lavoura } \\
\text { perman. }\end{array}$ & $\begin{array}{c}\text { Lavouras } \\
\text { tempor. }\end{array}$ & $\begin{array}{c}\text { Terras de } \\
\text { lav. temp } \\
\text { p. desc. }\end{array}$ & $\begin{array}{c}\text { Pastagens } \\
\text { naturais }\end{array}$ & $\begin{array}{c}\text { Pastagens } \\
\text { plantadas }\end{array}$ & $\begin{array}{c}\text { Matas e } \\
\text { florestais } \\
\text { naturais }\end{array}$ & $\begin{array}{c}\text { Matas } \\
\text { plantadas }\end{array}$ & $\begin{array}{c}\text { Terras } \\
\text { não } \\
\text { utilizadas }\end{array}$ \\
\hline MS & 28.501 & 1.847 .459 & 195.762 & 9.658 .224 & 12.144 .529 & 4.170 .597 & 454.251 & 583.530 \\
MT & 136.605 & 1.992 .838 & 426.100 & 9.685 .306 & 6.719 .064 & 14.126 .813 & 26.171 & 2.176 .434 \\
GO & 62.974 & 2.865 .225 & 396.747 & 9.569 .989 & 11.324 .595 & 2.828 .529 & 83.630 & 1.227 .461 \\
DF & 8.556 & 76.938 & 7.096 & 78.850 & 63.555 & 21.426 & 23.540 & 14.282 \\
\hline
\end{tabular}

Fonte: IBGE, Censo Agropecuário, 1985.

\section{Tabela 5 Utilização de terras no Centro-Oeste, 1996 (hectares)}

\begin{tabular}{lrrrrrrrrr}
\hline & $\begin{array}{c}\text { Lavoura } \\
\text { perman. }\end{array}$ & $\begin{array}{c}\text { Lavouras } \\
\text { tempor. }\end{array}$ & $\begin{array}{c}\text { Terras } \\
\text { lav. temp. } \\
\text { p. desc. }\end{array}$ & $\begin{array}{c}\text { Pastagens } \\
\text { naturais }\end{array}$ & $\begin{array}{c}\text { Pastagens } \\
\text { plantadas }\end{array}$ & $\begin{array}{c}\text { Matas } \\
\text { florestais } \\
\text { naturais }\end{array}$ & $\begin{array}{c}\text { Matas } \\
\text { plantadas }\end{array}$ & $\begin{array}{c}\text { Terras } \\
\text { não } \\
\text { utilizadas }\end{array}$ \\
\hline MS & 16.215 & 1.367 .496 & 118.185 & 6.082 .778 & 15.727 .930 & 5.696 .659 & 181.080 & 403.943 \\
MT & 169.734 & 2.782 .011 & 494.418 & 6.189 .573 & 15.262 .488 & 21.475 .795 & 67.829 & 1.446 .048 \\
GO & 55.787 & 2.119 .066 & 257.641 & 5.137 .285 & 14.267 .411 & 3.774 .654 & 72.652 & 545.549 \\
DF & 5.101 & 61.243 & 4.799 & 34.005 & 62.443 & 27.470 & 19.980 & 11.645 \\
\hline
\end{tabular}

Fonte: IBGE, Censo Agropecuário, 1996.

Com a crise econômica instalada nos anos 1980 e a implantação de sucessivos planos econômicos, esses programas sofreram uma redução orçamentária considerável, fazendo com que alguns chegassem à extinção. Ao mesmo tempo, ocorreu a diminuição do papel do Governo Federal no planejamento regional. A Superintendência do Centro-Oeste (SUDECO) foi extinta pelo Governo Collor em $1990^{1}$.

Desde o início dos anos 1990 o governo federal vem planejando diversos projetos e programas - dentre eles, a implantação de ferrovias (ver Mapa 4) e hidrovias (ver

\footnotetext{
${ }^{1}$ A SUDECO foi recriada pela presidente Dilma Rousseff no ano de 2011. A superintendência está vinculada ao Ministério da Integração Regional. Este ministério retomou as políticas públicas de desenvolvimento regional, e o órgão federal tem a missão de descentralizar os programas de desenvolvimento no Brasil. Para mais informações, acessar o site da Superintendência: http://www.sudeco.gov.br/institucional.
} 
Mapa 5) - que buscam novamente dotar a região Centro-Oeste de uma infraestrutura capaz de induzir o desenvolvimento econômico. São iniciativas bastante controversas, sobretudo as hidrovias, pois poderão provocar impactos ambientais e sociais. Estes projetos têm o objetivo de ampliar as áreas de produção de energia, transportes e, mais uma vez, a agricultura. Com o Programa de Aceleração do Crescimento (PAC), lançado em 2007, os projetos de grande vulto começaram a ser executados de forma mais sistemática. A meta do governo federal é a de ampliar o modal ferroviário para $40 \mathrm{mil} \mathrm{km}$ até o ano de 2020 . A região Centro-Oeste será contemplada com a Ferrovia de Integração CentroOeste (FICO), com previsão de possuir $1.638 \mathrm{~km}$, que faz parte dos projetos mais amplos da Ferrovia Transcontinental e da Ferrovia Norte-Sul ${ }^{2}$.

O Mapa 4 ilustra o que foi e o que será realizado nas obras do PAC para a expansão da malha ferroviária na região Centro-Oeste. Sem dúvida, este processo implicaria em mudanças substanciais no panorama econômico e ambiental da região. A possibilidade de encurtar distâncias e de diminuição nos custos dos transportes ampliaria a margem de lucro dos investimentos agropecuários e agroindustriais.

\section{Mapa 4 Projeto de implantação de ferrovias na região Centro-Oeste do Brasil}
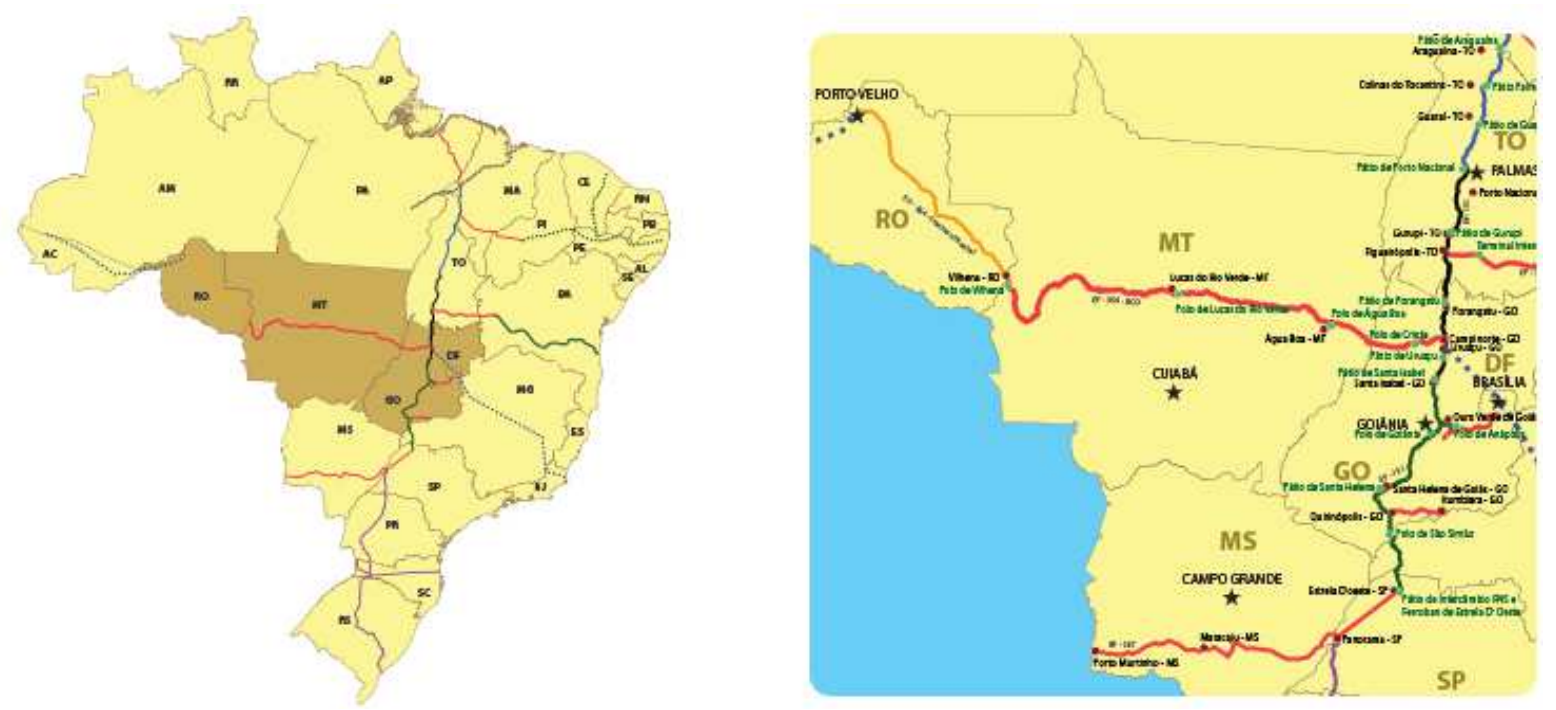

Fonte: Valec (2015).

No que se refere as hidrovias, o objetivo governamental também era a diminuição de custos e o de acelerar o transporte das mercadorias. Os estados beneficiados

\footnotetext{
${ }^{2}$ Informações disponíveis no site da empresa pública VALEC: $\underline{\text { http://www.valec.gov.br/acoes }}$ programas/FNSFerroviaNorteSul.php.
} 
são os de Goiás, Minas Gerais, Mato Grosso do Sul, Paraná e São Paulo. De acordo com o Ministério do Planejamento ${ }^{3}$, em 2015, os investimentos previstos para as obras na Hidrovia Paraná-Tietê são de R \$ 57.780.000,00 (cinquenta e sete milhões e setecentos e oitenta mil reais), o estágio das intervenções estatais é o de ainda em execução, com 30\% das obras concluídas. O Mapa 5 permite visualizar a geografia da bacia Paraná-Tietê, que tem o potencial de escoar cerca de 11,5 milhões de toneladas de cargas. Esse número é o dobro da movimentação de produtos que é realizada atualmente ${ }^{4}$, lembrando que somente o modal rodoviário é utilizado.

\section{Mapa 5 Hidrovia Paraná-Tietê}

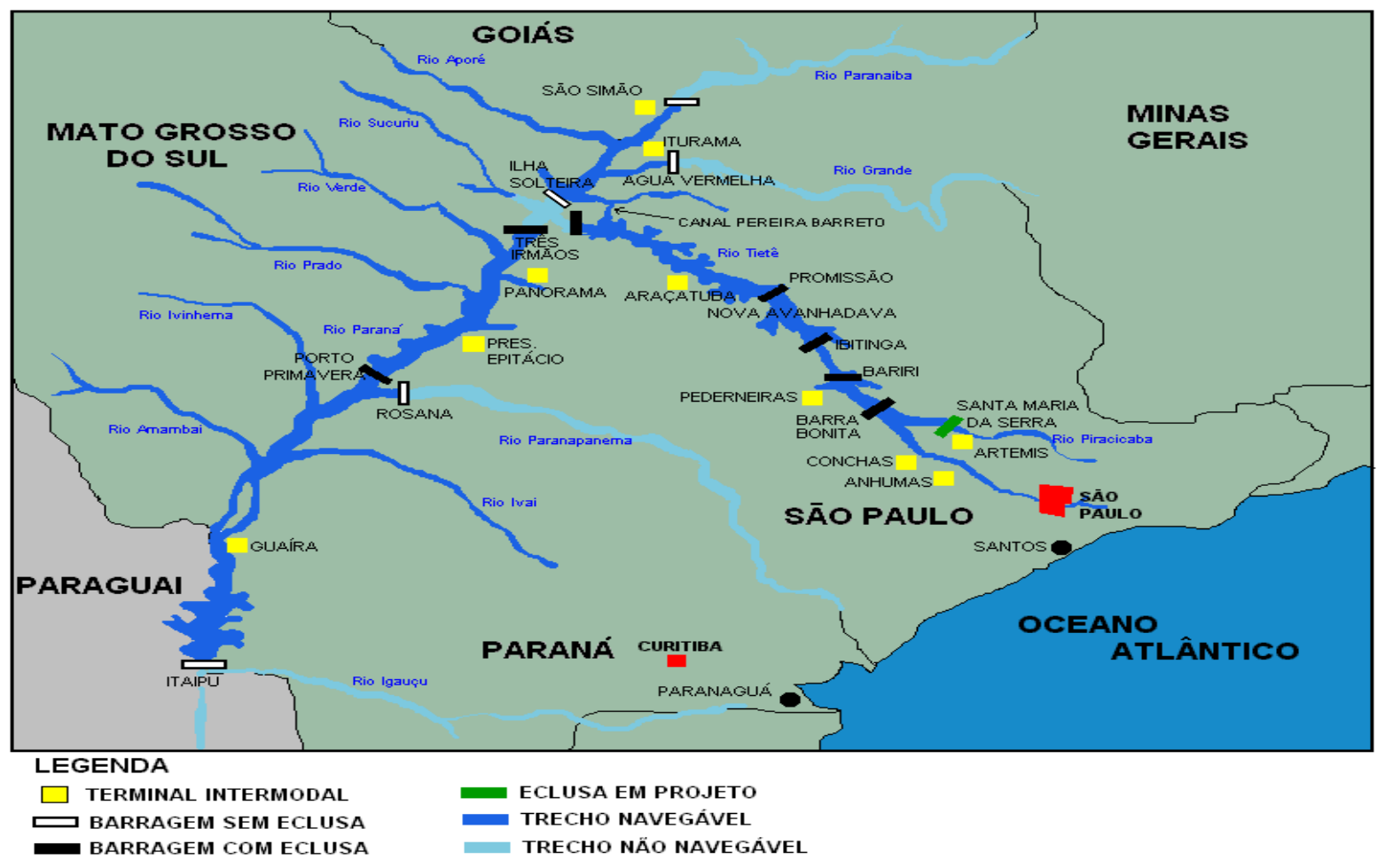

Fonte: SEPLAN-GO (2002, p. 54).

Embora os investimentos governamentais nas politicas de ocupação produtiva do Centro-Oeste trouxeram resultados positivos em indicadores econômicos, Pires (2000) observou algumas transformações sociais e ambientais na região devido a essa política de ocupação das últimas décadas. Podemos destacar que à medida que as políticas de desenvolvimento favoreceram a ocupação agrícola houve a

\footnotetext{
3 Informações disponíveis no site de acompanhamento das obras do PAC: http://www.pac.gov.br/obra/90039.

4 Informação disponível no site Portal Brasil: http://www.brasil.gov.br/infraestrutura/ 2013/10/obras-na-hidrovia-tiete-parana-recebem-r-134-milhoes.
} 
ampliação da taxa de desmatamento do Cerrado; o aumento da erosão dos solos e contaminação das águas pelo uso dos agrotóxicos; o aumento do êxodo rural, uma vez que a mão de obra disponível no campo foi pouco absorvida; e o aumento da concentração de renda, pois os incentivos agrícolas convergiram às grandes propriedades.

\section{A nova expansão agroindustrial do Centro-Oeste: o complexo sucroenergético no século XXI}

A partir de 2005 houve na região Centro-Oeste a expansão de um novo complexo industrial, a canavieira. O Plano Nacional de Agroenergia (2006-2011) incentivou a produção de biocombustíveis, especialmente o etanol da cana-de-açúcar. De São Paulo, as plantações de cana expandiram-se em direção ao Cerrado brasileiro, como resultado, entre outros motivos, do Zoneamento Agroecológico da Cana, que foi estabelecido pelo Decreto $\mathrm{n}^{0} \quad 6.077$ de 2009. O Zoneamento Agroecológico permitiu que no bioma do Cerrado pudesse ocorrer o avanço da plantação das lavouras de cana-de-açúcar (MANZAT'TO et al., 2009).

Dados do Instituto Nacional de Pesquisa Espacial (INPE), coletados no sistema CANASAT $^{5}$, indicam que mais de 9.4 milhões de hectares de cana na região Centro-Sul ${ }^{6}$ do Brasil foram plantados na safra 2013/2014, significando quase que o dobro da safra 2005/2006, quando a plantação de cana ocupou 4.632.111 hectares na mesma região. A cultura da cana ainda está crescendo em todas as regiões do país, entretanto, 87,4\% da área plantada na safra 2014/2015 está localizada na região Centro-Sul, com mais da metade do cultivo no bioma Cerrado. O estado de São Paulo continua sendo o maior produtor com 52\% da plantação brasileira de cana, seguido por Goiás com 9,5\%, Minas Gerais com 8,9\%, Mato Grosso com 8,8\%, Mato Grosso do Sul com 7,4\% e Paraná com 7,1\% (CONAB, 2014).

A expansão do complexo industrial canavieiro para o Centro-Oeste teve suporte substancial da Petrobrás, do Banco Nacional de Desenvolvimento Econômico e Social (BNDES) e do Fundo Constitucional do Centro-Oeste (FCO). O BNDES tem investido conjuntamente com a Financiadora de Estudos e Projetos (FINEP) no apoio à inovação tecnológica no setor sucroenergético. Em 2011, o BNDES e

\footnotetext{
${ }^{5}$ O projeto CANASAT é o monitoramento anual, via satélite, do cultivo e da produção de canade-açúcar no Centro-Sul do Brasil, coordenado pelo INPE. Para mais detalhes acessar o endereço http://www.dsr.inpe.br/canasat.

${ }^{6} \mathrm{Na}$ pesquisa do INPE disponibilizada no site da CANASAT é considerada a região Centro-Sul do Brasil a área que cobre os estados de São Paulo, Goiás, Minas Gerais, Mato Grosso, Mato Grosso do Sul, Paraná, Rio de Janeiro e Espírito Santo.
} 
a FINEP apoiaram 35 projetos de inovação tecnológica no setor industrial canavieiro, totalizando 2,5 bilhões de reais em investimentos. No ano seguinte, foram 4 bilhões de reais destinados à política de incentivo ao desenvolvimento tecnológico do setor. Desde que foi lançado o programa das agências do governo federal, os fundos de financiamentos foram ampliados e permitiu-se a tomada de empréstimos as companhias internacionais, estimulando a internacionalização do capital da indústria canavieira (McKAY et al., 2014).

De acordo com a Secretaria de Planejamento do Estado de Goiás (SEPLAN), de 2006 a 2009 o Fundo Constitucional do Centro-Oeste aprovou o financiamento de 329 milhões de reais para o as usinas de álcool e açúcar no estado. Nos quatros anos analisados, o FCO autorizou a maioria dos recursos entre os anos de 2006 e 2007, datas que coincidem com o lançamento e implementação do Plano Nacional de Agroenergia (PIETRAFESA, SAUER e SANTOS, 2011).

Apesar do argumento oficial do Governo de Goiás de que o aumento da produção de etanol no estado deve-se a "vocação para o agronegócio", houveram muitos estímulos governamentais. Além do investimento direto, incentivos fiscais, mais precisamente renúncias de impostos por parte do governo estadual. De acordo com Sauer e Pietrafesa (2012), o poder público do estado de Goiás deu isenção para o setor sucroenergético na ordem de 28,1 bilhões de reais em 2009. Nenhum outro setor da economia goiana, por meio do Programa de Desenvolvimento Industrial de Goiás (PRODUZIR), recebeu tantos incentivos fiscais quanto o complexo industrial canavieiro.

Acrescentado aos recursos e estímulos públicos, bem como a falta de iniciativas de proteção ambiental, a expansão da indústria sucroenergética no Centro-Oeste desfrutou de mais dois fatores. O primeiro refere-se às vantagens topográficas, uma vez que o terreno é plano e o solo teve aperfeiçoamentos como resultado da produções de outras culturas agrícolas (soja e pastagens, por exemplo). O segundo, a construção de infraestrutura. Em 2011, a Logum Logística - uma join venture formada pela Petrobrás, a Copersucar, a Raízen, a Odebrecht/ETH, Camargo Corrêa e Uniduto Logística - recebeu 924 milhões de reais de financiamento do BNDES para começar a construir um grande alcoolduto, interligando os estados de Goiás, Minas Gerais e São Paulo. O sistema será capaz de transportar até 21 bilhões de litros por ano e irá levar etanol ao porto de Santos e para os principais centros de consumo (WILKINSON; HERRERA, 2010).

\section{Conclusão}

Do exposto no artigo podemos perceber que o incentivo às atividades agropecuárias no Centro-Oeste foi primordial para o desenvolvimento econômico, urbano e populacional da região. Os estados de Goiás, Mato Grosso e Mato 
Grosso do Sul se inseriram, inicialmente, no planejamento da economia nacional como áreas para a produção de produtos alimentícios e matéria-prima para abastecer as regiões industrializadas. Posteriormente, os complexos agrícolas estruturaram suas próprias indústrias, caracterizando-se pelo uso de alta tecnologia, bem como pela consolidação como fonte de itens para exportação.

O desenvolvimento dessa economia rural permitiu o processo de urbanização no Centro-Oeste. Cidades de pequeno e médio porte foram criadas na medida em que avança o interesse de empresários do Sul e do Sudeste e dos fazendeiros da região na expansão das atividades agropecuárias. Os baixos preços das terras, até meados da década de 1980, contribuíram para a ocupação do Centro-Oeste. O contingente populacional na região era de aproximadamente 3 milhões de pessoas em 1960, no censo de 2010 esse número passa para um pouco mais de 14 milhões de habitantes, o que demonstra a expansão do povoamento nos estados que compõem o Centro-Oeste brasileiro.

As políticas governamentais tiveram papel central em todo esse processo de desenvolvimento do interior do Brasil, somente pela iniciativa privada não seria possível a ocupação produtiva e populacional dessa parte do território nacional. Iniciada com o Estado Novo, as políticas públicas da "Marcha para o Oeste" direcionaram recursos financeiros e isenções fiscais para que o Centro-Oeste pudesse desenvolver atividades econômicas com competividade tecnológica e de inserção tanto no mercado nacional quanto no internacional.

O complexo industrial canavieiro é um exemplo dessa ação proativa e impulsionadora do aparato estatal na promoção do desenvolvimento na regional. Esse setor correspondeu ao último ramo agrícola a buscar novas oportunidades de negócios no Centro-Oeste brasileiro. Para alcançar o objetivo proposto, o governo federal e os governos estaduais facilitaram a entrada da indústria sucroenergética na região. A licença ambiental para o uso do solo constituiu fator essencial para essa nova expansão agrícola. No bioma Cerrado, que cobre grande parte dos estados que compõem o Centro-Oeste, foi liberado o plantio da cana-de-açúcar e, a partir desse momento, houve a instalação de grande contingente de usina de etanol e de açúcar em Goiás, Mato Grosso e Mato Grosso do Sul. A partir das reflexões trabalhadas nesse artigo, fica uma questão para ser analisada em futuras pesquisas: o desenvolvimento econômico do Centro-Oeste por meio das atividades agrícolas já esgotou suas possibilidades, necessitando mudar o paradigma desenvolvimentista, ou ainda há espaço para a expansão de novos complexos industriais derivados do meio rural? 


\section{Referências}

CONAB. Companhia Nacional de Abastecimento. Acompanhamento da safra brasileira de cana-de-açúcar: safra 2014/15 - $3^{0}$ levantamento. CONAB, 2014.

CONFERENNCIA DAS NAÇÕES UNIDAS SOBRE MEIO AMBIENTE E DESENVOLVIMENTO. 1992. Rio de Janeiro. A Agenda 21. Brasília, DF. Senado Federal, 1996.

Comissão Mundial sobre Meio Ambiente e Desenvolvimento. Nosso Futuro Comum. Rio de Janeiro, Fundação Getúlio Vargas, 1988, 46p.

ESTEVAM, L. O tempo da transformação: estrutura e dinâmica da formação de Goiás. Goiânia: Editora do Autor, 1998.

HELFAND, S. M.; REZENDE, G. C. Mudanças na distribuição espacial da produção de grãos, aves e suínos no Brasil: O papel do Centro-Oeste. Rio de Janeiro: IPEA, 1998. (IPEA 611).

LENhArO, A. A Sacralização da Política. 2. ed. Campinas: Ed. Papirus, 1986.

McKAY, Ben et al. The politics of sugarcane flexing in Brazil and beyond: TNI piece series on flex crops and commodities. Traditional Institute, 2014.

MANZATTO, Celso et al. Zoneamento agroecológico da cana-de-açúcar: expandir a produção, preservar a vida, garantir o futuro. Embrapa Solos, 2009.

PIETRAFESA, José Paulo. A grande travessia: agricultura familiar e qualidade de vida. Tese (Doutorado em Sociologia). Departamento de Sociologia. Universidade de Brasília. Brasília, DF. 2002.

A utilização de tecnologia na agropecuária: nova divisão do trabalho no meio rural. In: ROCHA, Cleonice; TEJERINA-garro, Francisco Leonardo; PIETRAFESA, José Paulo. Cerrado, sociedade e ambiente: desenvolvimento sustentável em Goiás. Goiânia: Editora da UCG, 2008.

PIETRAFESA, José Paulo; SAUER, Sergio. Agrocombustíveis: nova dinâmica na velha fronteira, terceira marcha a ocupar o bioma Cerrado. In: J.M.AAgricola (Ed.). Cerrado, energia e sustentabilidade. Goiânia: PUC, 2012. 
PIETRAFESA, Jose Paulo; SAUER, Sergio; SANTOS, Ana Elizabeth. Políticas de recursos públicos na expansão dos agrocombustíveis em Goiás: ocupação de novos espaços em áreas de Cerrado. In: PIETRAFESA, José Paulo; SILVA, Sandro Sutra. Transformação do Cerrado: Progresso, consumo e natureza. Goiânia: PUC, 2011.

PIRES, Mauro de Oliveira. A trajetória do conceito de desenvolvimento sustentável na transição paradigmática. In. BRAGA, Maria Lucia de Santana; DUARTE, Laura Maria Goulart. Tristes Cerrados, sociedade e biodiversidade. Brasília, DF: Paralelo 15, 1998.

Região Centro Oeste: consolidando a fronteira. Aspectos da região relevantes para atuação conjunta das Organizações não Governamentais. Brasília, out. 2000. Mimeografado.

PORTO, Newton Marcos Leone. O transporte aéreo nos projetos de integração nacional no centro-oeste e no norte do Brasil 1930-1940. 2004. Dissertação (Mestrado em História). Faculdade de Ciências Humanas e Filosofia da Universidade Federal de Goiás, Goiânia, 2004.

SACHS, Ignacy. Estratégias de transição para o século XXI: desenvolvimento e meio ambiente. São Paulo: Studio Nobel/Fundação do Desenvolvimento Administrativo, 1993.

SILVEIRA FILHO, V. R. Cenário atual da viação agrícola no Brasil. Tese de mestrado, 2004. Instituto Tecnológico da Aeronáutica (ITA). São José dos Campos. 2004.

SILVA, Sandro Dutra. O sentido da Brasilidade e a questão regional. 2004. Dissertação (Mestrado em História). Universidade Federal de Goiás, 2004.

WILKINSON, John; HERRERA, Selena. Biofuels in Brazil: Debates and impacts. Journal of Peasant Studies, n. 37, v. 4, p. 749-768, 2010.

VAZ, Eber. Aspectos Histórico-Econômicos de Goiás: 1930-1960. Revista Estudos (Goiânia), Universidade Católica de Goiás, v. 16, p. 107-112, 1989.

VALEC Engenharia, Construções e Ferrovias S.A. Ferrovia Norte-Sul - FNS. Disponível em: http://www.valec.gov.br/acoes programas/FNSFFerroviaNorte Sul.php. Acesso em: 15 out. 2015. 
Endereço para correspondência:

Pedro_Araújo Pietrafesa - pedro.pietrafesa@gmail.com Avenida Universitária, 1440, Setor Universitário 74.605-010 Goiânia/GO, Brasil

José Paulo Pietrafesa - jppietrafesa@gmail.com Rua 227, Quadra 66, Número 3.669, 5. Andar 74.605-080 Goiânia/GO, Brasil

92 | Revista Brasileira de Desenvolvimento Regional, Blumenau, 3 (2), P. 73-92, primaVera de 2015 